\title{
Interprofessional Resource Centre: a knowledge translation strategy
}

This article was published in the following Dove Press journal:

Advances in Medical Education and Practice

19 January 2011

Number of times this article has been viewed

\section{Christine Patterson ${ }^{1,2}$ \\ Julie Vohra' \\ David Price ${ }^{3}$ \\ Gladys Peachey' \\ Heather Arthur ${ }^{1,4}$ \\ Patricia Ellis' \\ Rob Mariani ${ }^{5}$ \\ Paul Dymel ${ }^{5}$ \\ Ellen Spencer ${ }^{5}$ \\ Kevin Timms ${ }^{5}$ \\ Ellis Westwood ${ }^{5}$}

'School of Nursing, Faculty of Health Sciences, McMaster University, Hamilton, ON, Canada; ${ }^{2}$ Ontario Primary Health Care Nurse Practitioner Program, McMaster University, Hamilton, ON, Canada; ${ }^{3}$ Department of Family Medicine, McMaster University, Hamilton, ON, Canada; ${ }^{4}$ Heart and Stroke Foundation of Ontario/Michael G. DeGroote Endowed Chair in Cardiovascular Nursing Research, McMaster University, Hamilton, ON, Canada; ${ }^{5}$ Ascentum, Ottawa, ON, Canada
Correspondence: Christine Patterson McMaster University, Faculty of Health Sciences, School of Nursing, HSC-2J2 IB, I200 Main St.West, Hamilton, ON L8N 3Z5, Canada

Tel + I 9055259140 ext 22304

Fax + I 9055700667

Email cpatter@mcmaster.ca

\begin{abstract}
The Interprofessional Resource Centre (IRC) was based on an extensive literature search and a provincial consultative process that involved administrators, health care providers, educators, preceptors, and alternative and complementary health care providers from different disciplines. Information from the literature review was synthesized into a logic model that served as a preliminary outline for the IRC to be further developed during the stakeholder consultation. The findings from the literature were triangulated with the opinions of different groups of key stakeholders who participated in three different methods of data collection: 1) a large-scale deliberative survey, 2) an in-person dialogue, and 3) targeted questionnaires. The result of this process was an online tool that presents information on what needs to be considered when planning interprofessional practice and education within an organization with the purpose of: 1) building capacity within agencies for interprofessional, collaborative practice; 2) providing preceptors with educational strategies to develop interprofessional competencies in their students; 3) promoting the use of technology as a strategy for knowledge transfer within the agencies and between educational institutions; and 4) developing an evaluation plan to measure interprofessional practice and education.
\end{abstract}

Keywords: interprofessional teams, health care delivery, change

\section{Introduction}

Health Force Ontario is a provincial strategy to ensure access to the right number and mix of health care professionals in Ontario, with a particular focus on interprofessional care. ${ }^{1}$ Transition to an interprofessional culture of care requires carefully planned strategies based on an understanding of the determinants and processes that influence interprofessional education and practice. ${ }^{2,3}$ In the document entitled "Interprofessional Care: a Blueprint for Action in Ontario", one of the strategies for advancing interprofessional care was through the use of e-health strategies. ${ }^{1}$ Based on this recommendation, Health Force Ontario funded the development of the Interprofessional Resource Centre (IRC).

In general, a resource center is an online tool that supports action by providing easy access to necessary information and is organized in such a way that it follows the process of meeting a particular purpose. The IRC is unique among other online tools in that it is a stepwise approach to supporting an organization's effort in advancing interprofessional practice and education. The overarching framework that guided the content development of the IRC was the five stages of organizational innovation as defined by Rogers in $2003 .{ }^{4}$ Based on the key concepts within the framework, the IRC presents information on what needs to be considered when planning interprofessional 
practice and education within an organization with the purpose of: 1) building capacity within agencies for interprofessional, collaborative practice; 2) providing preceptors with educational strategies to develop interprofessional competencies in their students; 3 ) promoting the use of technology as a strategy for knowledge transfer within the agencies and between educational institutions; and 4) developing an evaluation plan to measure interprofessional practice and education.

The internet is a knowledge transfer agent. The advantages of Web-delivered resources are cost-effectiveness, flexibility, and convenience, which are essential outcomes in busy clinical agencies. Providers involved in interprofessional collaborative initiatives can access the IRC content repeatedly and at their convenience. The content can be downloadable and referred to as needed. Because the critical issue of time availability limits providers' ability to engage in time-consuming searches, a focused approach to content synthesis in user-friendly formats streamlines knowledge transfer. Utilization of the internet also provides the opportunity to develop resource centers within a reasonable cost, once the infrastructure and process have been established.

This paper describes the developmental process of an online IRC to report interprofessional key stakeholders' opinions on content and format and demonstrates that through this participatory approach to development the IRC reflects the reality of the clinical environment. The IRC assists administrators, preceptors, and health care providers in primary health care agencies to develop supportive environments for interprofessional practice and education through information that is immediately available to them and their students. It allows for deliberate planning based on stakeholder needs. The IRC was developed using inclusive consensus-based methods.

\section{Developmental process of the IRC Literature review}

To guide the development of the IRC, a preliminary review of the literature was completed. Information from primary quantitative and qualitative studies, reviews, and gray literature (eg, discussion documents, research reports, and government documents) was included in the review. Health electronic databases were searched, including: Medline, CINAHL, and EMBase, as well as business databases such as Business Source Complete and General Business File. Additionally, internet searches were conducted using search strategy keywords to identify gray literature. The reference lists of relevant papers were also reviewed as another source for identifying relevant information.

Information from the literature review was synthesized into a logic model that served as a preliminary outline for the IRC to be further developed during the stakeholder consultation. The following were identified as key focus areas for primary health care organizations implementing interprofessional practice and education: education and professional development, organizational learning capacity, legislative/regulatory issues, communications/marketing, and practice environment. Under each of these areas, activities were identified as important for successful change., $2,3,5-25$ It was these activities that helped shape the content of the IRC in the beginning stages of development. Within each of the steps, targeted literature reviews were completed to continue to expand on the content of the website.

\section{The consultative process}

The three key groups of stakeholders identified for this project included 1) health care providers from various disciplines, 2) administrators and educators, and 3) preceptors and complementary/alternative medicine (CAM) providers. The recruitment strategy required seeking out known, as well as unknown, key stakeholders in the province of Ontario. Therefore, participants were recruited through key individuals or chief executive officers of stakeholder organizations for the completion of consultative surveys. The contacts were asked to support the recruitment process within their organization or with other providers or educators within their networks or communities. This recruitment approach identified a broad community of individuals who were interested in and/or champions of interprofessional practice and education. Such breadth of representation could not have been achieved through a more traditional recruitment process.

\section{Methods of data collection}

The three different methods of data collection were designed to reach different groups of key stakeholders; these methods were: 1) a large-scale deliberative survey, 2) an in-person dialogue, and 3) targeted questionnaires.

\section{Large-scale deliberative survey}

The large-scale deliberative survey was designed to reach out to our key stakeholder groups: health care providers from various disciplines, administrators, and educators. The approach was a shift away from traditional surveying to one based on a more deliberate approach. To accomplish 
this, the survey included information to consider that would help the respondent better understand both the subject matter and the rationale for the questions being posed. The objective of the survey was to identify gaps and priorities for the proposed IRC framework, as well as to increase understanding of how the IRC will be used and what supporting tools are desired.

Based on a literature review, the authors created outlines of the key areas for inclusion in the survey. Briefly, the survey asked participants to rate the significance of challenges to interprofessional practice, such as preparing for change, building teams, engaging in dialogue, developing networks and partnerships, and evaluating progress. Participants were also asked to rate the significance of challenges to interprofessional care environments, such as developing strategic plans, conducting environmental scans, managing change for redesigning the practice environment, and identifying organizational processes needing change. Finally, they were asked to rate the significance of challenges to interprofessional education, including preparing for preceptorship and providing interprofessional education.

\section{In-person dialogue}

The in-person dialogue session was designed to bring together a group of administrators from across the province to explore ideas about interprofessional practice and care in a small group format. Diverse perspectives from representatives with differing demographics (including setting size, geography, and scope of practice) created the setting for a rich dialogue. The objective of the in-person session was to explore what interprofessional care means and looks like in their settings, what knowledge resources are needed to build capacity for interprofessional care in community agencies, and how a Web-based resource center could support planning for change.

\section{Targeted survey questionnaires}

The third element was targeted survey questionnaires for both educators/preceptors and CAM providers. It was important to consider CAM providers as members of the interprofessional team and to ensure that the IRC reflected the required integration strategies of this role within the agency. ${ }^{11}$ The National Center for Complementary and Alternative Medicine refers to the combining of mainstream medical therapies and CAM as integrative medicine. ${ }^{26}$ Therefore, the creation of integrative health care teams will result in redefining roles and a change in how services are delivered. ${ }^{11}$ Based on this knowledge, the inclusion of content on how to work with
CAM providers provides a valuable dimension to the IRC. The experience of integration could then pass to students as CAM providers relate their unique perspective of the challenge created in coordinating "interparadigm" teams. ${ }^{11}$

The questionnaires were shorter than the deliberative survey and did not include the same level of context-setting information. For the preceptor survey, participants were asked to rate important factors for achieving interprofessionality, list the key consideration for successful interprofessional preceptorship programs, and rate the importance of evaluation themes. The CAM survey asked respondents to 1) elaborate on the meaning of interprofessional practice from a professional, practice, and organizational perspective; 2) describe an ideal interprofessional partnership; 3) rate key challenges to overcome (including working with administrators and other health care providers, attitudes and lack of knowledge, coordinating care, patient health surveillance, and liability concerns); and 4) list the key consideration for success.

\section{Analysis of the data}

The approach to data analysis for the stakeholder consultation data was to examine frequencies of quantitative data. The results were used to generate an outline for content development for the IRC.

\section{Results \\ Demographics}

Respondents represented all geographic regions of Ontario. A variety of health care providers participated in the survey, eg, dieticians (19.1\%), nutritionists (15.5\%), administrators $(21.1 \%)$, massage therapists $(13.5 \%)$, nurses $(11.2 \%)$, pharmacists $(4 \%)$, occupational therapists $(2.2 \%)$, physicians $(2.2 \%)$, physiotherapists $(1.6 \%)$, and social workers $(1.3 \%)$. They worked in a variety of interprofessional teams within family health teams and community health centers. Respondents worked at various levels of team functioning, from multidisciplinary $(n=89)$ to transdisciplinary $(n=69)$, with half stating that their team was interdisciplinary $(n=222)$. The majority of the participants had been involved in interprofessional practice and education.

\section{Deliberative survey}

There were 445 responses to the deliberative survey. Of the 445 participants who started the survey, 91 of them did not continue after completion of the demographic information. The completion rate for the survey was $61 \%(n=273)$. 
The profile of participants with respect to health professions, setting, and geographical location did not change after the initial dropout or at the completion of the survey. The number of responses for each item varies as respondents only answered questions that were applicable to their current situation.

\section{Challenges to becoming interprofessional} Interprofessional practice

When asked about the challenges they face regarding interprofessional practice, on a scale of 1 (smaller challenge) to 5 (bigger challenge), the respondents indicated the following as 4 or 5 . Some of the more significant challenges to interprofessional practice involve not only the systemic factors of having political will and appropriate leadership but team-focused issues such as the ability to collectively make decisions, communicate, and evaluate success (Table 1).

\section{Care environments}

When asked about the challenges they face regarding care environments, on a scale of 1 (smaller challenge) to 5 (bigger

Table I Challenges to interprofessional practice

\begin{tabular}{|c|c|c|}
\hline Item & Frequency & Percent \\
\hline $\begin{array}{l}\text { Political will and buy-in by those in power } \\
\text { positions }(n=354)\end{array}$ & 210 & 59.3 \\
\hline $\begin{array}{l}\text { Leadership to build interprofessional } \\
\text { champions to sustain interprofessional } \\
\text { practice in the agency }(\mathrm{n}=353)\end{array}$ & 206 & 58.4 \\
\hline $\begin{array}{l}\text { Knowledge of group dynamics that results } \\
\text { in shared leadership and an integrated, } \\
\text { comprehensive approach to patient care } \\
(n=353)\end{array}$ & 167 & 47.3 \\
\hline $\begin{array}{l}\text { Understanding the scope of practice of } \\
\text { other health professionals }(n=355)\end{array}$ & 147 & 41.4 \\
\hline $\begin{array}{l}\text { Developing trust when working alongside } \\
\text { other health professions }(n=356)\end{array}$ & 161 & 45.2 \\
\hline $\begin{array}{l}\text { Understanding the impact of team-based } \\
\text { collaboration on patient outcomes }(n=35 I)\end{array}$ & 124 & 35.3 \\
\hline $\begin{array}{l}\text { Productive communication among team } \\
\text { members }(n=354)\end{array}$ & 207 & 48.6 \\
\hline $\begin{array}{l}\text { Managing conflicts that may arise between } \\
\text { members of interprofessional care teams } \\
(n=353)\end{array}$ & 148 & 42.0 \\
\hline Collective decision-making $(\mathrm{n}=354)$ & $|8|$ & 51.1 \\
\hline $\begin{array}{l}\text { Understanding of the legal, professional, } \\
\text { and regulatory guidelines and standards } \\
\text { of different providers }(n=353)\end{array}$ & 169 & 47.8 \\
\hline $\begin{array}{l}\text { Practice considerations when working with } \\
\text { complementary/alternative providers } \\
(n=350)\end{array}$ & 153 & 43.7 \\
\hline $\begin{array}{l}\text { Planning time for informal and formal } \\
\text { interactions }(n=354)\end{array}$ & 227 & 64.1 \\
\hline $\begin{array}{l}\text { Evaluation indicators to measure success } \\
(\mathrm{n}=353)\end{array}$ & 219 & 62.0 \\
\hline
\end{tabular}

challenge), the respondents indicated the following as 4 or 5 . Participants reported that success starts with creating the vision, managing the change, and recruiting interprofessional expertise (Table 2).

\section{Interprofessional education}

When asked about the challenges they face regarding interprofessional education, on a scale of 1 (smaller challenge) to 5 (bigger challenge), the respondents indicated the following as 4 or 5 . The important challenges in delivering interprofessional education were centered on supportive preceptorship through information on teaching strategies for interprofessional competencies and success indicators that measure them (Table 3).

The challenges faced by participants were used to direct development of the IRC. The content needed to address the various challenges was woven throughout the website, and through the use of navigators the user is directed to various parts of the IRC with related information.

\section{In-person sessions analysis}

During the in-person sessions, responses were gathered from 14 participants who represented family health team administrators from a variety of geographic locations in Ontario as well as an urban, a suburban, and a rural mix. When respondents were asked about the most significant challenge in promoting interprofessional, collaborative practice in

Table 2 Challenges to care environments

\begin{tabular}{|c|c|c|}
\hline Item & Frequency & Percent \\
\hline $\begin{array}{l}\text { Developing a vision and mission statement } \\
\text { that defines interprofessional collaboration } \\
(\mathrm{n}=327)\end{array}$ & 117 & 35.8 \\
\hline $\begin{array}{l}\text { Negotiating shared areas of practice and } \\
\text { providers working to their full scope of } \\
\text { practice }(n=323)\end{array}$ & 161 & 49.9 \\
\hline Leading the change $(n=325)$ & 188 & 57.8 \\
\hline $\begin{array}{l}\text { Conducting an internal environmental } \\
\text { scan }(n=3 \mid 2)\end{array}$ & 109 & 35.0 \\
\hline $\begin{array}{l}\text { Conducting an external environmental } \\
\text { scan }(n=3 \mid 5)\end{array}$ & 133 & 42.2 \\
\hline Managing resistance to change $(n=325)$ & 202 & 62.1 \\
\hline $\begin{array}{l}\text { Managing errors made when leading } \\
\text { change }(n=322)\end{array}$ & $|4|$ & 43.7 \\
\hline $\begin{array}{l}\text { Developing an environment for formal } \\
\text { and informal interaction }(n=32 \mathrm{I})\end{array}$ & 169 & 52.6 \\
\hline $\begin{array}{l}\text { Recruiting to identify interprofessional, } \\
\text { collaborative experience and expertise } \\
(n=319)\end{array}$ & 138 & 43.3 \\
\hline $\begin{array}{l}\text { A governance structure that supports } \\
\text { interprofessional collaboration }(n=322)\end{array}$ & $|7|$ & 53.1 \\
\hline Developing performance indicators $(n=322)$ & 180 & 40.5 \\
\hline Ensuring patient safety $(n=322)$ & 43 & 9.7 \\
\hline
\end{tabular}


Table 3 Challenges to interprofessional education

\begin{tabular}{|c|c|c|}
\hline Item & Frequency & Percent \\
\hline $\begin{array}{l}\text { Selecting preceptors to deliver } \\
\text { interprofessional educational } \\
\text { experiences to students }(n=297)\end{array}$ & 113 & 38.0 \\
\hline $\begin{array}{l}\text { Developing the strategy for } \\
\text { entry of students into } \\
\text { the agency }(n=294)\end{array}$ & 92 & 31.3 \\
\hline $\begin{array}{l}\text { Developing teaching strategies } \\
\text { for the interprofessional } \\
\text { education competencies }(n=296)\end{array}$ & 124 & 41.8 \\
\hline $\begin{array}{l}\text { Identifying success indicators } \\
\text { for the interprofessional } \\
\text { education competencies }(n=295)\end{array}$ & 139 & 47.2 \\
\hline Giving feedback to students $(n=295)$ & 51 & 17.3 \\
\hline Teaching online $(n=283)$ & 99 & 35.0 \\
\hline Evaluating preceptorship programs $(\mathrm{n}=285)$ & 96 & 33.7 \\
\hline
\end{tabular}

their organization, the top responses were understanding the scope of practice $(28.6 \%, \mathrm{n}=4)$, physician buy-in $(21.4 \%$, $\mathrm{n}=3)$, sharing power/common goals $(21.4 \%, \mathrm{n}=3)$, and agreement on the meaning of interprofessional $(14.3 \%, \mathrm{n}=2)$. When respondents were asked about the least significant challenge in promoting interprofessional, collaborative practice in their organization, the top responses were training of students $(50.0 \%, \mathrm{n}=7)$, physical space/multiple sites $(14.3 \%, \mathrm{n}=2)$, resolving disagreements $(14.3 \%, \mathrm{n}=2)$, and knowing when to be collaborative $(14.3 \%, \mathrm{n}=2)$.

\section{Targeted survey analysis CAM providers}

There were 10 responses to the targeted survey for complementary/alternative medicine. Respondents represented various geographic locations of Ontario, urban and rural, but were concentrated around the Greater Toronto area. Types of CAM practices included homeopathy, naturopathy, and natural therapies.

When respondents were asked to rate the significance of challenges to becoming part of an interprofessional team in primary health care agencies, the highest rated $(90 \%$ of respondents rated as quite significant or very significant) challenges were:

- Working with administrators to develop an organizational vision that supports freedom of choice and the use of CAM

- Working with stakeholders, administrators, and practitioners on the definition of CAM and how it fulfills the agency's policies and procedures

- Working with other health care providers to expand the delivery care model and how providers work beyond the current medical model
- Agreeing on the level of medical science needed to support the use of CAM in treatment plans

- Establishing clinical expectations for reporting and accountability

- Establishing networks with other providers in an interprofessional team, such as physicians, physiotherapists, and nurse practitioners

- Being able to refer to other members of an interprofessional team.

\section{Preceptors}

There were 35 responses to the targeted survey for preceptors. Respondents represented all geographic regions of Ontario, a mixture of urban $(n=14)$ and rural $(n=16)$, as well as those working in a variety of interprofessional teams, including local health integration networks, family health teams, and community health centers. Representatives from colleges and universities were also included.

When asked to rate the importance of each topic for achieving interprofessionality, at least $85.7 \%$ of respondents indicated the following topics as quite to very significant: trust, commitment, collaboration, communication, and teamwork (Table 4).

Respondents $(n=31)$ were asked to rate the importance of providing information under the four topics for interprofessional practice. Of the four potential areas, participants reported that content on how to achieve a supportive organizational environment for successful interprofessional education is significant and reaffirmed the need for appropriate success indicators for interprofessional competencies. Frequency denotes the number of respondents that rated the item as important or very important (Table 5).

Using the findings from the three stakeholder consultation activities, the IRC was created. The respondents' level of experience, challenges, and priorities regarding interprofessional practice guided the content development for the IRC so that the website responds to all of the issues identified in the stakeholder consultation.

The IRC was designed, based on the results of this study, as a step-by-step approach to support an organization's

Table 4 Achieving interprofessionality

\begin{tabular}{lll}
\hline Item & Frequency & Percent \\
\hline Commitment to the team & 34 & 97.1 \\
Trust in others & 34 & 97.1 \\
Building and sharing knowledge & 32 & 91.4 \\
Collaboration & 34 & 97.1 \\
Capacity to dialogue & 31 & 88.6 \\
Team dynamics & 34 & 97.1 \\
\hline
\end{tabular}


Table 5 Important information for interprofessional practice

\begin{tabular}{lll}
\hline Item & Frequency & Percent \\
\hline $\begin{array}{l}\text { Indicators of success for interprofessional } \\
\text { competencies }\end{array}$ & 30 & 85.7 \\
$\begin{array}{l}\text { Organizational conditions that need to be } \\
\text { in place for delivering interprofessional }\end{array}$ & 29 & 83.0 \\
$\begin{array}{l}\text { education } \\
\begin{array}{l}\text { Teaching strategies to assist preceptors in } \\
\text { providing an interprofessional experience }\end{array}\end{array}$ & 26 & \\
$\begin{array}{l}\text { Pitfalls people have faced trying to develop } \\
\text { a preceptorship program }\end{array}$ & 24 & 74.3 \\
\hline
\end{tabular}

effort in advancing interprofessional practice and education (www.interprofessionalresourcecentre.ca). From the home page, users can view an introduction clip that provides an overview of the information available on the website. They can also browse through the following six key areas: 1) preparing a supportive environment, 2) committing to organizational champions, 3) examining patient care services, 4) interprofessional change, 5) developing preceptorship, and 6) evaluation.

\section{Discussion}

Primary health care agencies are now required to move toward interprofessional care. ${ }^{1}$ Interprofessional care is dependent on a supportive environment, interprofessional practice matched to the type of service required, and the education of future providers. It is essential that service providers moving to an interprofessional model collaborate in planning for the change. ${ }^{2-4}$ Organizations that comprise the team's broader network of care should be consulted/included to ensure that they are able to partner effectively with the team to optimize patient care.

How does the IRC support planning and implementation? First, the IRC provides easy access to information that has been synthesized from the literature and knowledge users. The information can be used for adopting and diffusing the innovation. In this case, the innovation is interprofessional practice and education in primary health care agencies. It starts with the initial step of preparing supportive environments. At this point, administrators and providers consider how important interprofessional practice and education are to promoting the organization's goals and what information needs to be collected to plan for these initiatives. As users consider adoption of interprofessional practice, they reflect on the types of challenges for leadership and stakeholders. Three administrative challenges were identified: assessing the environment, creating buy-in, and building vision. . $^{14,17,22,23}$ There is particular emphasis on scanning the external and internal environments to determine internal and external opportunities and threats, determining the leadership required to move forward, and strategizing the complexities of implementing the change.

As administrators and providers move into the implementation phase, information is outlined in a stepwise process that leads the users to examine their patient care services for the purpose of coming to some consensus on the level of teamwork required to meet the objectives. Through questioning and reflection, the team can identify where they are with respect to their functioning and where they would like to go. An objective analysis of the needs of the community guides this process and allows for a match of identified needs to the requirements of interprofessional care. The team is supported in change through a detailed account of how to develop their own personal interprofessional strategy. Finally, an implementation evaluation plan assists administrators and providers to assess the level at which the interprofessional initiatives have become integrated into the culture of the organization.

\section{Acknowledgments}

The authors acknowledge administrators, providers, preceptors, and faculty from family health teams, community health centers, professional organizations, and educational institutions in Ontario who participated and generously gave their input. We would also like to thank Health Force Ontario for the support that made this project possible.

\section{Disclosure}

The authors report no conflicts of interest in this work.

\section{References}

1. Health Force Ontario. Interprofessional Care: a Blueprint for Action in Ontario. Ontario, Canada: Government of Ontario; 2007.

2. D'Amour D, Oandasan I. Interprofessionality as the field of interprofessional practice and interprofessional education: an emerging concept. J Interprof Care. 2005;19(Suppl 1):8-20.

3. D'Amour D, Ferrada-Videla M, San Martin Rodriguez L, Beaulieu MD. The conceptual basis for interprofessional collaboration: core concepts and theoretical frameworks. J Interprof Care. 2005;19(Suppl 1): 116-131.

4. Rogers E. Diffusion of Innovations. 5th ed. New York, NY: Free Press; 2003.

5. Barker KK, Bosco C, Oandasan IF. Factors in implementing interprofessional education and collaborative practice initiatives: findings from key informant interviews. J Interprof Care. 2005;19(2):166-176.

6. Bruhn JG, Chesney AP. Diagnosing the health of the organizations. In: Hein EC, editor. Contemporary Leadership Behavior. Philadelphia, PA: Lippincott-Raven; 1998.

7. Canadian Nurse Practitioner Initiative. Implementation and Evaluation Toolkit for Nurse Practitioners in Canada. 2006. Available from: http:// www.cnpi.ca/documents/pdf/Toolkit_Implementation_Evaluation_NP_e. pdf. Accessed January 15, 2008.

8. Claire L, Gordon MF, Marshall M, Wilson F, Hunt T. Interprofessional capability: a developing framework for interprofessional education. Nurse Educ Pract. 2005;5:230-237. 
9. Cooper H, Spencer-Dawe E, McLean E. Beginning the process of teamwork: design, implementation and evaluation of an inter-professional education intervention for first year undergraduate students. J Interprof Care. 2005;19(5):492-508.

10. Oandasan I, Reeves S. Key elements for interprofessional education part 1: the learner, the educator, and the learning context. $J$ Interprof Care. 2005;Suppl 1:21-38.

11. Patterson C, Arthur H. A model for implementing integrative practice in health care agencies. Integrative Med Insights. 2008;3:1-7.

12. Reeves S, Zwarenstein M, Goldman J, et al. Interprofessional education effects on professional practice and health care outcomes. Cochrane Database Syst Rev. 2008;1:CD002213.

13. San Martin Rodriguez L, Beaulieu M, D’Amour D, Ferrada-Videla M. The determinants of successful collaboration: a review of theoretical and empirical studies. J Interprof Care. 2005;Suppl 1:132-147.

14. Upshaw VM, Kaluzny AD, McLaughlin CP. CQI, transformation, and the learning organization. In: Bennis WG, Benne KD, Chin R, Corey KE, editors. The Planning of Change. 3rd ed. New York, NY: Holt, Rinehart and Winston; 1976.

15. Walsh CL, Gordon MF, Marshall M, Wilson F, Hunt T. Interprofessional capability: a developing framework for interprofessional education. Nurse Educ Pract. 2005;5:230-237.

16. Zwarenstein M, Reeves S, Perrier L. Effectiveness of pre-licensure interdisciplinary education and post-licensure collaborative interventions. J Interprof Care. 2005;19(Suppl 1):148-165.
17. Xyrichis A, Ream E. Teamwork: a concept analysis. J Adv Nurs. 2008;61(2):232-241.

18. Bucher R. On the natural history of health care occupations. Work Occup. 1988;152:131-147.

19. Marquis BL, Huston CJ. Leadership Roles and Management Functions in Nursing: Theory and Application. 4th ed. Philadephia, PA: Lippincott Williams \& Wilkins; 2003.

20. Barrett J, Curran V, Glynn L, Godwin M. CHSRF Synthesis: Interprofessional Collaboration and Quality Primary Healthcare. Ottawa, Canada: Canadian Health Services Research Foundation; 2007.

21. Davenport TH. Process Innovation: Reengineering Work through Information Technology. Boston: Boston Business School Press; 1993.

22. Ford JD. Organizational change as shifting conversations. J Organ Change Manag. 1999;12(6):480-490.

23. Moon MY. Making sense of common sense for change management buy-in. Manag Decis. 2009;47(3):518-532.

24. Poulton BC, West MA. The determinants of effectiveness in primary health care teams. J Interprof Care. 1999;13(1):7-18.

25. McGregor D. The Human Side of Enterprise. Toronto, Canada: McGraw-Hill; 1960.

26. National Centre of Complementary and Alternative Medicine. What is complementary and alternative medicine. 2004. Available from: http://nccam.nih.gov/health/whatiscam. Accessed Nov 252010
Advances in Medical Education and Practice

\section{Publish your work in this journal}

Advances in Medical Education and Practice is an international, peerreviewed, open access journal that aims to present and publish research on Medical Education covering medical, dental, nursing and allied healthcare professional education. The journal covers undergraduate education, postgraduate training and continuing medical education

\section{Dovepress}

including emerging trends and innovative models linking education, research, and healthcare services. The manuscript management system is completely online and includes a very quick and fair peer-review system. Visit http://www.dovepress.com/testimonials.php to read real quotes from published authors.

Submit your manuscript here: http://www.dovepress.com/advances-in-medical-education-and-practice-journal 